\title{
S. BOULANGER, Le vignoble du Jura
}

Bordeaux, Presses universitaires, 2004

\section{Jean-Pierre Husson}

\section{(2) OpenEdition}

\section{Journals}

Édition électronique

URL : http://journals.openedition.org/rge/857

DOI : $10.4000 /$ rge. 857

ISSN : 2108-6478

\section{Éditeur}

Association des géographes de l'Est

Édition imprimée

Date de publication : 1 juin 2004

Pagination : 169

ISSN : 0035-3213

\section{Référence électronique}

Jean-Pierre Husson, «S. Boulanger, Le vignoble du Jura », Revue Géographique de l'Est [En ligne], vol. 44 / 3-4 | 2004, mis en ligne le 21 décembre 2009, consulté le 25 septembre 2020. URL : http:// journals.openedition.org/rge/857 ; DOI : https://doi.org/10.4000/rge.857

Ce document a été généré automatiquement le 25 septembre 2020

Tous droits réservés 


\title{
S. BOULANGER, Le vignoble du Jura
}

\author{
Bordeaux, Presses universitaires, 2004
}

\author{
Jean-Pierre Husson
}

\section{RÉFÉRENCE}

S. BOULANGER, Le vignoble du Jura, Bordeaux : Presses universitaires, 2004, 427 p.

1 Dans un fort volume abondamment illustré, Sylvaine Boulanger reprend les principaux résultats de sa thèse. L'objectif affiché n'est pas de rédiger une monographie sur les vignobles jurassiens mais de croiser les faits inscrits sur la trame chronologique avec une analyse portant sur les processus, scénarios et rythmes d'évolution des paysages viticoles restés ici assez pérennes. Les surfaces concernées s'organisent en archipel, prenant l'aspect d'un chapelet étiré sur près de $80 \mathrm{~km}$ de long. L'actuel vignoble (2 000 ha) représente à peine $10 \%$ de la surface maximale atteinte en 1873 . Les sources consultées montrent que l'ancien vignoble offrait un aspect désordonné. Planté en foule, et avec une forte densité de ceps par pièces de terre, il était reproduit par la technique du provinage. La culture à la main permettait d'occuper des parcelles très accidentées, avec des pentes allant jusqu'à $30 \%$. Marqué par un double mouvement de concentration et de réduction débuté depuis 1950, ce vignoble replanté en ligne après la crise phylloxérique est essentiel pour véhiculer une image valorisante, noble, publicisée voire festive des reculées du Revermont.

Découpé en deux parties, le livre s'appuie sur la succession des étapes vécues ou subies, puis sur l'étude des causes conjuguées pour expliquer le déclin poursuivi jusqu'au début de l'Après-Guerre. Les dégâts tardifs provoqués par la crise phylloxérique (1893-1900) précédant les effets dévastateurs de la Première Guerre, parenthèse située dans une longue période d'exode rural. La déprise, la rétractation des finages et son corrélat, l'extension des friches, sont révélateurs d'une crise rurale profonde, durable. Cette dernière fut aggravée par la fermeture du marché suisse aux vins jurassiens (1892) puis, dans les années Trente, par les effets de la grande dépression économique. 
3 Moribond vers 1950, le vignoble jurassien entame ensuite une renaissance remarquée alors que beaucoup de vignobles septentrionaux périclitent, ne se relèvent plus. La reprise s'effectue avec la délimitation de six AOC (dont Arbois, Château-Chalon, L'Etoile) et cinq cépages. Ce redressement conserve une certaine diversité paysagère, foncière et parcellaire en fonction de la place relative occupée par la vigne dans les finages. Le coeur du vignoble se situe autour d'Arbois-Pupillin. Ailleurs existent des paysages semi ouverts (Polligny) ou encore en marqueterie (sud du Revermont).

4 Complété par un glossaire et une abondante bibliographie, l'ouvrage de madame Sylvaine Boulanger contribue à la connaissance d'un vignoble septentrional original, porté par des acteurs dynamiques. L'approche du redressement est associée à l'analyse paysagère prise comme fil directeur de la recherche menée.

\section{AUTEURS}

\section{JEAN-PIERRE HUSSON}

Université de Nancy 2 